\title{
Qualitative and Quantitative Evaluation of Indirect Immuno- fluorescent H-2 Stain on Tissue Sections
}

\author{
David A: Saunders*, Theodore F. Beals** and Jane S. Schultz ${ }^{\dagger}$ \\ Departments of Human Genetics*t and Pathology** University of Michigan School of Medicine, \\ Ann Arbor, Michigan, and Veterans Administration Hospital ${ }^{* *},{ }^{\dagger}$ Ann Arbor, Michigan, U.S.A.
}

\begin{abstract}
We have utilized $\mathrm{H}-2$ specific antisera from congenic resistant donor recipient combinations to localize $\mathrm{H}-2$ antigens in tissue sections using the indirect immunofluorescent technique. $\mathrm{H}-2$ specific immunofluorescence is observed in spleen, kidney, and liver sections: however, especially with liver sections, there are cases in which the expected specific stain is weak or absent. In addition to microscopic evaluation by eye, we have employed a microscope attached photometer; recordings from this instrument differentiate positive from control stained spleen sections.
\end{abstract}

Received for publication 20 July, revised, accepted 27 December 1978

The tissue and organ distribution of $\mathrm{H}-2$ antigens has been determined by absorbing H-2 alloantisera with tissue homogenates. Such methods indicate that spleen and other lymphoid organs have a relatively high concentration of $\mathrm{H}-2$ antigens; several other tissues, including liver and kidney, also contain $\mathrm{H}-2$ antigens, though in more moderate concentrations than in spleen (for review see Edidin 1972 and Klein 1975). Based on the capacity of partially purified membrane preparations to absorb antibodies from anti- $\mathrm{H}-2$ sera and on the participation of $\mathrm{H}-2$ antigens in membrane mediated serological reactions against live cell suspensions (Klein 1975), $\mathrm{H}-2$ antigens have been localized subcellularly on surface membranes.

Previous investigators (Gervais 1968,
1972, Barnes et al. 1974) have reported the immunofluorescent localization of $\mathrm{H}-2$ in tissue sections from several organs including spleen, kidney, and liver. Their studies have confirmed that $\mathrm{H}-2$ antigens are associated with, if not an integral part of, cell membranes. In certain cell types there may also be $\mathrm{H}-2$ antigens in the cytoplasm. These authors raised alloantisera in recipients which were not $\mathrm{H}-2$ congenic with their immunizing donors; furthermore, Gervais employed neoplastic cells rather than normal lymphoid cells for the alloimmuizations. For both these reasons, it is possible that antigenic systems, other than the $\mathrm{H}-2$ system, made a substantial contribution to the fluorescent labeling demonstrated by these investigators.

We have utilized $\mathrm{H}-2$ specific antisera 


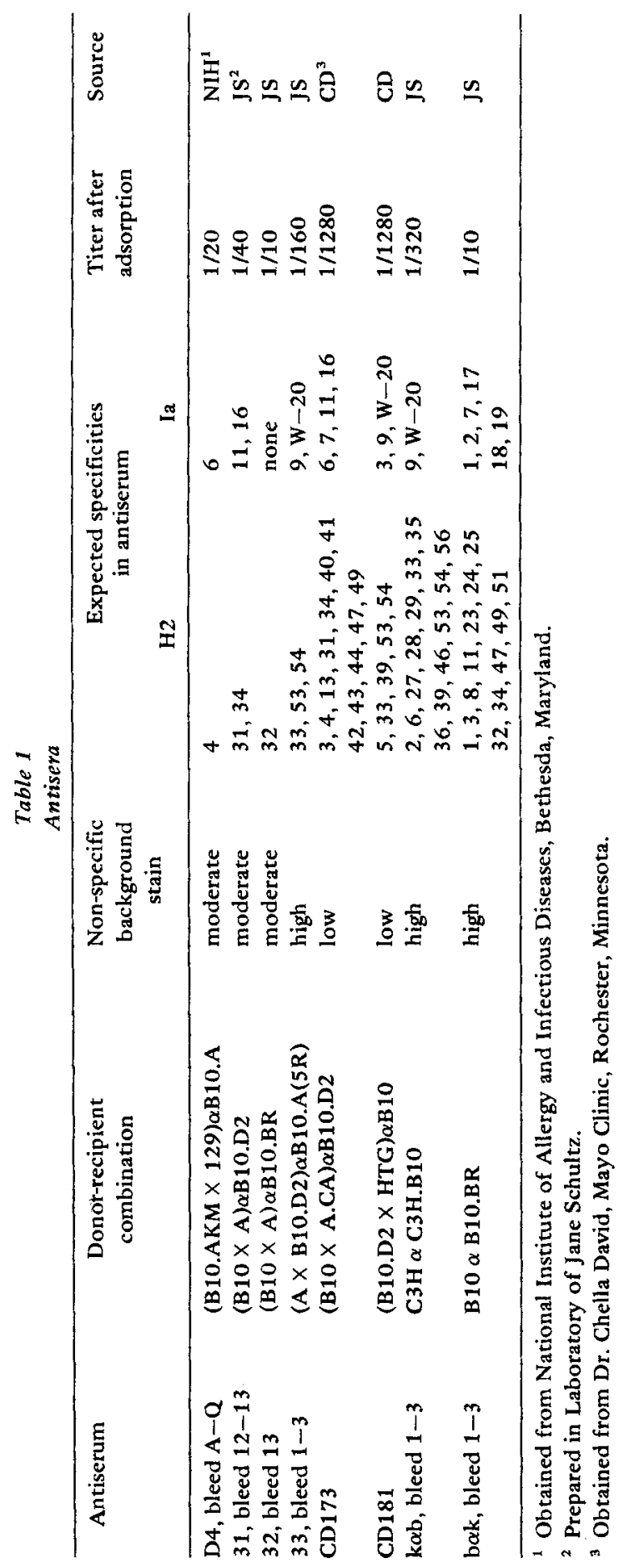


from congenic resistant donor-recipient combinations to determine the localization of $\mathrm{H}-2$ antigens in tissue sections by indirect immunofluorescence. Eight different alloantisera that are monospecific, oligospecific, or polyspecific for $\mathrm{H}-2$ specificities have been tested against tissues from five strains of mice differing at the $\mathrm{H}-2$ locus. Each alloantiserum is tested against tissue of the recipient strain and of strains that have putatively all or some of the antigenic specificities included in the antiserum. In spleen, liver and kidney sections we have, in many cases, noted specific immunofluorescent staining for $\mathrm{H}-2$ antigens, both by visual observations and by quantitative photometric techniques. These techniques, however, occasionally yield results which are not expected from the putative strain distribution of $\mathrm{H}-2$ antigenic specificities.

\section{Material and Methods}

Mice: Strains B10.A and B10.A(5R) were purchased from Jackson Laboratories, Bar Harbor, Maine. Other strains were obtained from stocks bred in our laboratory at the Ann Arbor Veterans Administration Hospital, or by Dr. John Niederhuber of the University of Michigan School of Medicine. Both the VA stocks and the University of Michigan stocks were originally obtained from Dr. Donald Shreffler, Washington University School of Medicine.

A $n t i-H-2$ sera (First layer sera): Table 1 lists all antisera including their sources, strain combinations employed for immunization, titers, and expected specificities. Immunizing tissues consist of suspensions of spleen, thymus, and lymph node (cervical, axillary, brachial, mesenteric, and inguinal cells). One donor is employed for about 10 recipients at each intraperitoneal immunization. Mice are immunized on weeks $1,4,5,9,13,17$ and 21 . Bleedings via the retro orbital sinus are obtained on weeks $6,7,8,10,11,12,14,15,16,18$, $19,20,22,23$, and 24 .

Cytotoxic antisera titers: Cytotoxic titers are determined by a modification of the method described by Amos (1976). Lymph node cells are purified on a ficoll-isopaque gradient, washed, counted, and incubated with dilutions of the sera in question, as well as with positive and negative control sera, in Falcon microtiter plates. Rabbit complement previously absorbed on agarose and diluted to an appropriate concentration is then added. The incubation medium throughour the test is Eagle's Minimal Essential Medium with Hank's salts plus $2 \%$ fetal calf serum. For each antiserum, the bleedings of highest titers are combined for further use.

Liver powder absarption of anti-H-2 sera: All anti-H-2 sera, except for normal sera and immune sera CD173 and CD181, are absorbed with liver powders prepared as described by Kwapinski (1972). Each serum is absorbed with acetone liver powder prepared from one or both parental strains of the $F_{1}$ in which the antiserum was produced. Four tenths of a $\mathrm{ml}$ of $\mathrm{a} 1$ in 4 dilution of serum is absorbed with $50 \mathrm{mg}$ of powder for $1 \mathrm{~h}$ at room temperature. The serum is then recovered by centrifugation for $1 / 2 \mathrm{~h}$ at $6600-9600 \mathrm{~g}$ and then retitered.

Conjugate: Fluorescein conjugated IgG fraction from rabbit anti-mouse IgG (heavy and light chains) (Lot 8864) was purchased from Cappel Laboratories, Cochranville, 
Pennsylvania. This IgG preparation is fractionated on DEAE-Sephadex-A-50 by the manufacturer both prior to and following conjugation.

Tissue preparation: Mice are sacrificed by cervical dislocation. Liver, spleen, and kidneys are immediately removed, cut into small pieces (approximately $4 \mathrm{~mm}^{3}$ ), and frozen in isopentane at $-70^{\circ} \mathrm{C}$. These organs are stored at $-80^{\circ} \mathrm{C}$ for up to 1 week. Tissues are embedded in O.C.T. compound (Lab-Tek Products, Naperville, Illinois), cut in $10 \mu \mathrm{m}$ thick sections at $-25^{\circ} \mathrm{C}$, and the sections air dried onto slides for 20 to $50 \mathrm{~min}$ prior to staining.

Section staining: Staining with anti- $\mathrm{H}-2$ serum follows the protocol described by Gervais (1968). The first layer normal sera and immune sera CD173 and CD181 are diluted 1 in 8 . Liver powder absorbed first layer sera are not further diluted. Fluorescein conjugate is diluted 1 in 4 . These dilutions give the highest specific stain intensity relative to generalized nonspecific background stain. After the final wash the preparations are mounted in Gelvatol 20-30 (equivalent to Elvanol) and stored at $4^{\circ} \mathrm{C}$ in the dark.

In each experimental series several anti-H-2 sera from Table 1 are employed. A given tissue and anti-H-2 serum can be expected to give one of the three reaction patterns based on reactions between that serum and lymphocytes of the inbred strain from which the tissue sections are obtained: firstly, no reaction (these are putative negative controls; the antiserum contains no antibodies reacting with $\mathrm{H}-2$ specificities found in this strain); secondly, full reaction (these are putative positive tests; the antiserum is produced by immunization with tissue of this $\mathrm{H}-2$ type), and thirdly, partial reactions (these are putative partial positives; only some of the specificities included in the antiserum are present in the tissue). Additional controls employ PBS in the place of the first layer (no mid-layer control) or a normal mouse serum first layer. Normal serum controls include a section incubated with autologous serum and a section incubated with heterologous serum. Sections treated only with PBS (autofluorescence controls) are included in several experiments.

Microscopy: Slides are observed on a Zeiss Research microscope with epifluorescent illumination, $40 \mathrm{X}$ objective 1.25 optivar setting, and $10 \mathrm{X}$ eye pieces. The lamp is an Osram Halgen-Bellphot rated at $12 \mathrm{~V}$, $100 \mathrm{~W}$. The primary filter is a Zeiss FITC filter and the secondary filter is a Zeiss $530 \mathrm{~K}$.

Measurements of the total fluorescence within selected microscopic fields of stained sections are obtained with a Zeiss photomultiplier and display unit. The filters are the same as those employed for visual observations. The recorded transmittance values are arbitrary relative units determined by the particular settings of the instrument. These are constant throughout the series of measurements so that readings between dfferent experiments are comparable. The selection and recording of fields is conducted rapidly in order to minimize fluorescence quenching, which we estimate to be 1 or $2 \%$.

\section{Results}

Staining of $\mathrm{H}-2$ antigens is observed in spleen, liver and kidney sections in several experiments. Spleen sections including no mid-layer controls, normal serum controls, and those incubated with anti-H-2 sera show a fluorescent stain outlining 
lymphocytes and a nonspecific, intense stain of the splenic trabeculae. The stain outlining lymphocytes is most intense in sections incubated with putatively positive or partially positive anti-H-2 sera. Individual cells in both the red and white pulp areas show the same degree of specific stain. However, since the lymphocytes are more densely packed in the white pulp, these areas appear to have the most specific stain. A spleen section stained with $\mathrm{H}-2$ specific serum and its negative control are shown in Fig. 1. In addition to the specific peripheral stain on lymphocytes, there is a nonspecific, diffuse background stain in all cells. This background stain is not due to autofluorescence, and its intensity varies with different anti-H-2 sera. Any one serum gives consistently bright or consistently weak nonspecific background stain in all experiments in which it is employed. Nonspecific background stain is therefore a characteristic of the antiserum.

Liver sections reacted with normal or immune sera stain at the sinus linings and at the hepatocyte periphery; the peripheral stain blends somewhat into the cytoplasm. Control sections of liver which are incubated with only the fluorescent conjugate and no anti- $\mathrm{H}-2$ or normal serum do not show cytoplasmic background stain and only a weak stain of sinus linings and hepatocyte periphery. In some experiments the sections stained with putatively positive or partially reacting anti-H-2 sera show a distinguishably more intense polygonal patterned, peripheral stain of the hepatocytes. We could not distinguish Kupffer cells in our sections. Positively stained and negative control liver sections are shown in Fig. 2. There is a nonspecific, cytoplasmic background stain similar to that seen in spleen; this stain varies among different sera but is constant in intensity for all experiments in which any given serum is used.

The renal tubules and Bowman's capsule of the cortical regions in all kidney sections (except the autofluorescent controls) are outlined by a stain which blends toward the interior of the tubules. There is also a very intense stain of glomerular blood vessels and mesangial tufts. Specific antigen stain can usually be distinguished by its increased intensity at the outline of the tubules and Bowman's capsule. Specifically stained and negative control sections of the kidney cortex are shown in Fig. 3. Stain is concentrated along the collecting tubules of the kidney medulla and usually shows increased intensity in putatively positive sections. The interior of the kidney tubules also has a nonspecific background stain similar to that observed in spleen and liver.

Several anti-H-2 sera nonspecifically stain nuclear membranes and thread-like projections of the nuclear membranes of liver and kidney sections with considerable interisity. The projections may be artifacts of the sectioning procedure. The brilliance of these nuclear reactions interferes in some cases with the observation of $\mathrm{H}-2$ specific staining. All immune sera used in these experiments (except CD178 and CD181, which do not give nuclear reactions) are, therefore, absorbed with liver powder. The absorption eliminates nonspecific nuclear stain but does not noticeably reduce the previously mentioned nonspecific background stain.

The antisera listed in Table 1 are employed to detect antigen distribution in spleen, liver and kidney from five mouse strains of different $\mathrm{H}-2$ types. The expected results and observations are presented in Table 2 in which all entries for a given organ type from a given strain represent a single experiment; thus, for a 

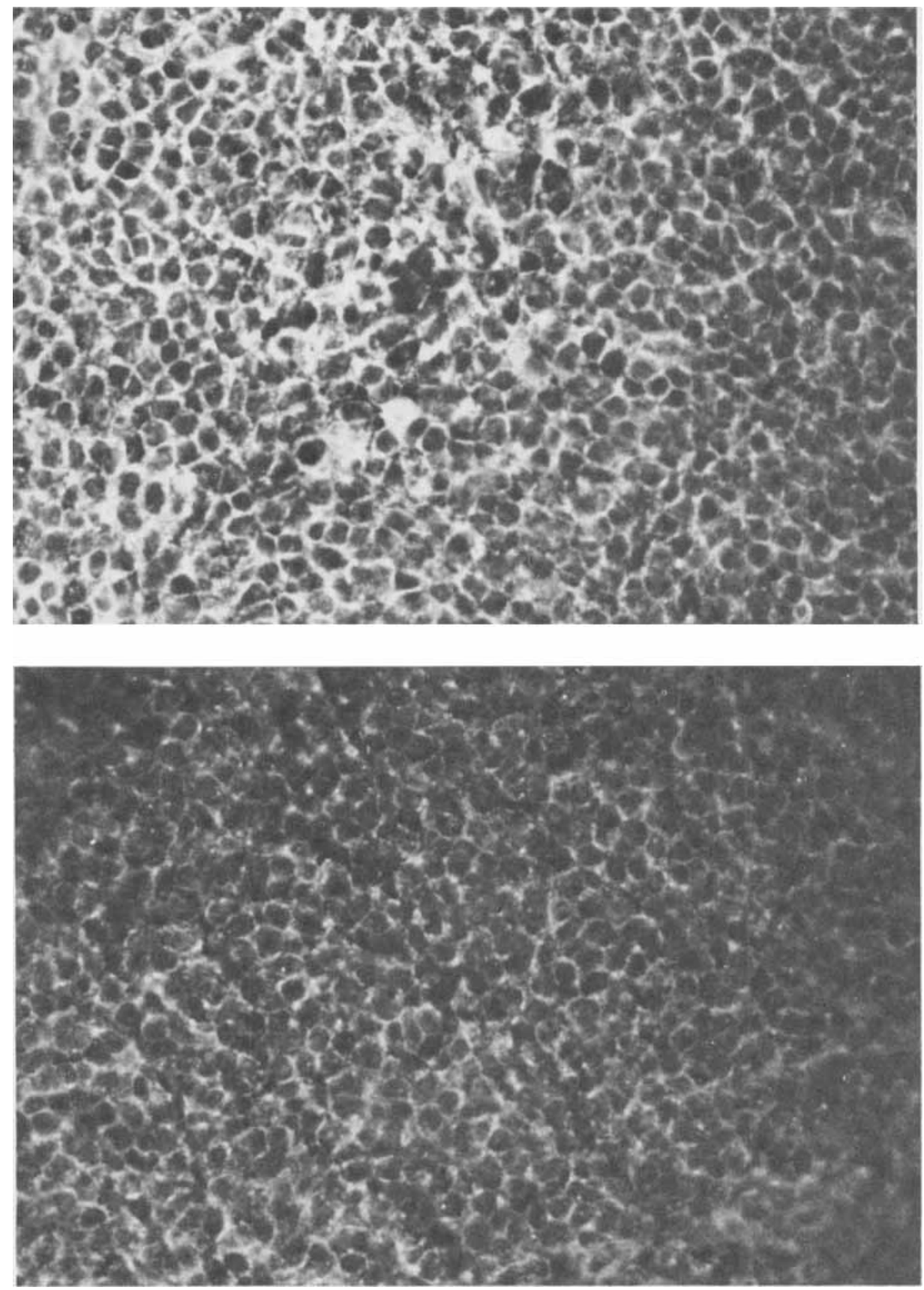

Figure 1. Indirect immunofluorescent stain of $\mathrm{H}-2$ antigens in $\mathrm{B} 10$ spleen sections. $\mathrm{A}$, positive stain with antiserum $33,53,54$. B, negative control stain with antiserum 32 . $\times 800$. 

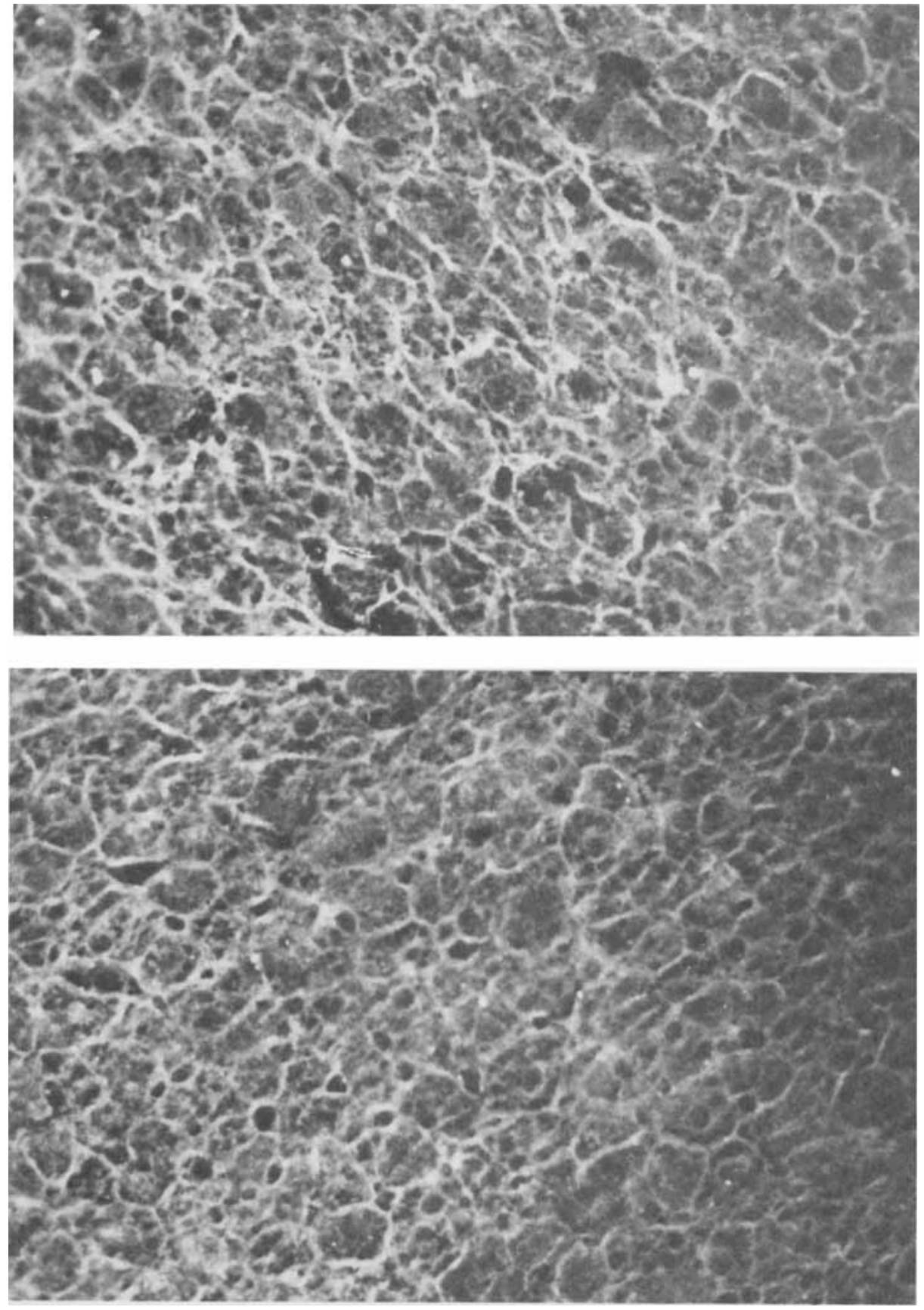

Figure 2. Indirect immunofluorescent stain of $\mathrm{H}-2$ antigens in $\mathrm{B} 10$ liver sections. A, positive stain with antiserum kab. B, negative control stain with antiserum $32 . \times 500$. 
given tissue the results of several putatively positive and negative reactions are compared under like conditions of tissue preparation, incubation, washing, and observation. The results in most cases agree with expectations. For the ambiguous cases, represented by plus-minus entries, the putatively positive tissues show staining only slightly brighter than that observed on putatively negative sections, while putatively negative sections have a stain only slightly less bright than that on putatively positive sections. Most sera show some strong reactions with putatively negative tissues and some weak reactions with putatively positive tissues. Except for C3H.OL kidney, the results for spleen and kidney section generally agree with expectations and this $\mathrm{C} 3 \mathrm{H} . \mathrm{OL}$ result may be due to staining of la antigens. However, on liver sections one often observes ambiguous results or failure of putatively positive experimental sera to give positive stains.

The intensity of stain on homogeneous white pulp areas of spleen sections was also evaluated photometrically and the results presented in Fig. 4. Each column of values represents a single experiment, thus different sera reacting with a given tissue type are compared under equivalent conditions of tissue preparation and staining procedure.

\section{Discussion}

The results in Table 2 and similar unreported data from this laboratory reveal that in several experiments putatively positive or partially positive sera specifically detect $\mathrm{H}-2$ antigens which are localized as reported by Gervais (1968, 1972). However, in some experiments, especially those utilizing liver sections, anti-H-2 sera that are putatively positive for a given strain fail to stain tissue sections from that strain. Staining is expected since these tissues have been shown by adsorption techniques to contain $\mathrm{H}-2$ antigens (Edidin 1972).

There is often moderate to intense stain at the site of $\mathrm{H}-2$ localization whether the first layer is normal serum, putatively positive antiserum or putatively negative antiserum. This interfering stain might actually be due to nonspecific accumulation of reagents in connective tissue adjacent to the site of $\mathrm{H}-2$ localization. Staining of the network of reticular fibers between the sinusoid lining and hepatic cell plates in liver may be the cause of the intense staining along roughly parallel lines which is sometimes observed on both negative control and specifically stained liver sections. There is no significant quantitative difference in accumulation of nonspecific stain between samples in which the first layer is heterologous or autologous normal serum. However putatively negative anti$\mathrm{H}-2$ serum sometimes shows greater nonspecific stain than normal serum. There is no evidence, however, that putatively negative antisera detect alloantigens unrelated to the $\mathrm{H}-2$ system.

Interpretation of results is also hampered by the presence of a nonspecific, general background stain. Some sera, such as $\mathrm{k}$ anti- $b$ and $b$ anti-k produced in our laboratory, show relatively high levels of background stain. On the other hand, sera CD173 and CD181 obtained from Dr. Chella David show very low degrees of background stain. In order to minimize the confounding effects of nonspecific background stain, one must compare sections stained with sera which show approximately equivalent backgrounds.

The levels of nonspecific background stain or specific anti-H-2 stain are not dependent on whether the alloantiserum is 

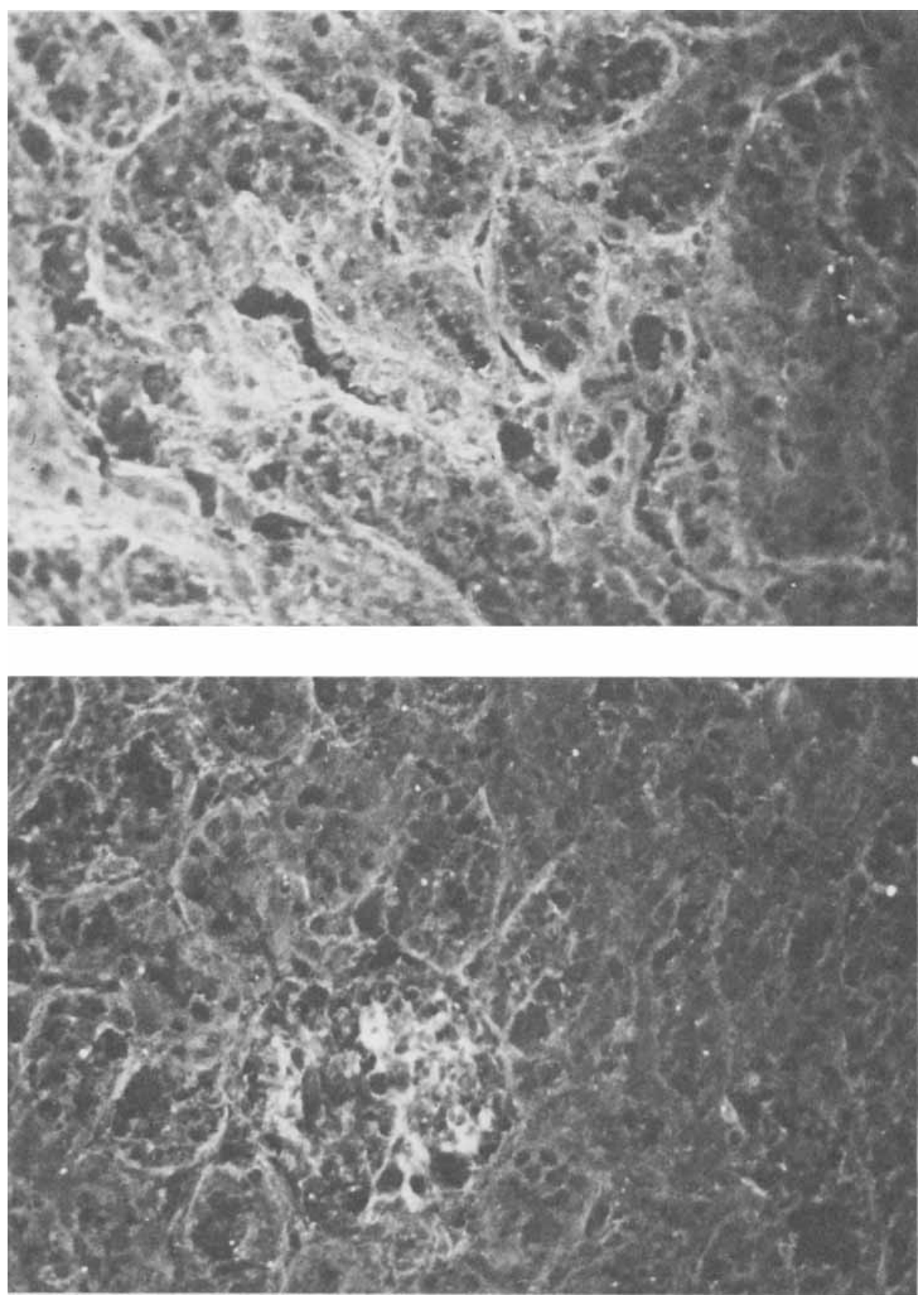

Figure 3. Indirect immunofluorescent stain of $\mathrm{H}-2$ antigens in B10 kidney sections. A, positive stain with antiserum $\mathrm{k} \alpha \mathrm{b}, \mathrm{B}$, negative control stain with antiserum $32 . \times 500$. 
Table 2

Results by visual examination

\begin{tabular}{|c|c|c|c|c|c|c|}
\hline \multirow[t]{2}{*}{ Serum } & & \multicolumn{5}{|c|}{ H-2 Type } \\
\hline & & $\mathbf{b}$ & $\mathrm{d}$ & $\mathrm{i}$ & $\mathrm{k}$ & 0 \\
\hline \multirow[t]{4}{*}{ D4 } & Expect & - & + & + & - & - \\
\hline & Liver & \pm & + & - & - & \pm \\
\hline & Kidney & ND & + & + & - & \pm \\
\hline & Spleen & - & + & ND & - & - \\
\hline \multirow[t]{4}{*}{31} & Expect & - & + & - & - & + \\
\hline & Liver & \pm & \pm & - & - & \pm \\
\hline & Kidney & - & + & - & - & \pm \\
\hline & Spleen & - & + & ND & ND & + \\
\hline \multirow[t]{4}{*}{32} & Expect & - & - & - & + & + \\
\hline & Liver & \pm & \pm & - & + & \pm \\
\hline & Kidney & - & - & \pm & + & \pm \\
\hline & Spleen & - & - & - & ND & + \\
\hline \multirow[t]{4}{*}{33} & Expect & + & - & + & - & - \\
\hline & Liver & \pm & \pm & + & - & - \\
\hline & Kidney & + & ND & + & - & - \\
\hline & Spleen & + & - & + & ND & - \\
\hline \multirow[t]{4}{*}{ CD 173} & Expect & - & + & $\mathrm{Pa}, \mathrm{b}, \mathrm{d}$ & $\mathrm{Pa}, \mathrm{b}$ & $\mathrm{Pa}, \mathrm{b}, \mathrm{c}$ \\
\hline & Liver & - & + & - & - & - \\
\hline & Kidney & - & + & + & + & - \\
\hline & Spleen & - & + & ND & ND & ++ \\
\hline \multirow[t]{4}{*}{ CD 181} & Expect & - & - & + & $\mathrm{Pa}, \mathrm{b}$ & $\mathrm{Pa}, \mathrm{b}$ \\
\hline & Liver & \pm & - & - & - & - \\
\hline & Kidney & + & - & + & + & - \\
\hline & Spleen & + & - & ND & + & + \\
\hline \multirow[t]{4}{*}{$k$ anti-b } & Expect & + & $\mathrm{Pa}, \mathrm{b}$ & $\mathrm{Pa}, \mathrm{b}, \mathrm{c}$ & - & $\mathrm{Pa}, \mathrm{b}$ \\
\hline & Liver & + & $+t$ & + & - & + \\
\hline & Kidney & ++ & + & ++ & \pm & + \\
\hline & Spleen & $+t$ & ++ & $+t$ & - & ++ \\
\hline \multirow[t]{4}{*}{ b anti-k } & Expect & - & $\mathrm{Pa}, \mathrm{b}$ & $\mathrm{Pa}, \mathrm{b}$ & + & $\mathrm{Pa}, \mathrm{b}, \mathrm{d}$ \\
\hline & Liver & \pm & \pm & \pm & + & \pm \\
\hline & Kidney & - & + & + & + & \pm \\
\hline & Spleen & - & ND & ND & ND & + \\
\hline \multirow[t]{4}{*}{ Normal Sera } & Expect & - & - & - & - & - \\
\hline & Liver & - & - & - & - & - \\
\hline & Kidney & - & - & - & - & - \\
\hline & Spleen & - & - & - & - & - \\
\hline
\end{tabular}

ND, Not determined.

+ , positive.

- , negative.

\pm , weak positive reaction.
$\mathrm{Pa}$, partial positive, $\mathrm{K}$ region public.

$\mathrm{Pb}$, partial positive, $\mathrm{D}$ region public.

$\mathrm{Pc}$, partial positive, $\mathrm{K}$ region private.

$\mathrm{Pd}$, partial positive, $\mathrm{D}$ region private. 
monospecific, oligospecific, or polyspecific. The data in Table 2 show that polyspecific antiserum $k$ anti-b generally gives a very strong specific reaction. Polyspecific sera CD173, CD181, and $b$ anti-k also give specific reactions but in some instances stain liver sections too weakly when a partial, rather than a fully positive, reaction is expected. Good staining shows a pattern of $\mathrm{H}-2$ reactivity which

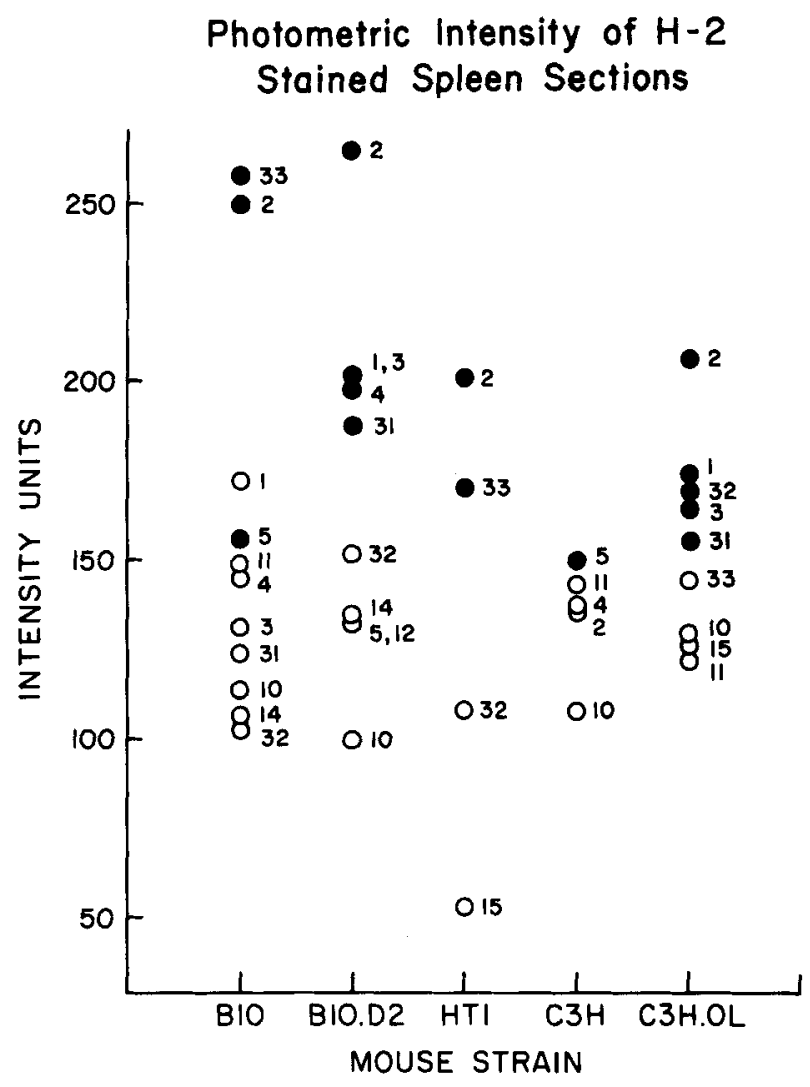

Figure 4. Vertical axis, transmittance units recorded by Zeiss photomultiplier and display unit. Horizontal axis, mouse strains from which spleen sections are obtained. Each point records the intensity of fluorescent stain on a spleen section after reaction with the indicated serum. An average of 4.8 readings are obtained for each section, and the average standard deviation is $6.2 \%$ of the recorded value. $(\bullet)$, serum expected to give positive reaction with indicated strain. $(0)$, serum expected to give no reaction with given strain. Serum code: 1 , b $\alpha k ; 2, k \alpha b ; 3$, CD173; 4, D4; 5, CD181; 10, no mid-layer control; 11, B10 normal serum; 12, B10.D2 normal serum; 13, HTI normal serum; 14, C3H normal serum; 15, C3H.OL normal serum; 31, anti 31,$34 ; 32$, anti $32 ; 33$, anti $33,53,54$. 
differs from the pattern shown by the specificities taken together. Therefore, none of these antigenic subsets are present in any particular pattern on any tissue or group of tissues.

Data present in Figure 4 indicate that nearly all the expected positive spleen sections have photomultiplier readings in the white pulp areas above the range of 150-155 units, while control samples have readings below this same cutoff range. Sections with intensity values that lie near the 150-155 range are ambiguous. Nonspecific background stain does affect the intensity recordings. In the control experiment in which serum $b$ anti-k is reacted with $B 10$ spleen, the excessively high reading is due to a high non-specific background stain. Values of photometer readings on liver sections do not show complete correlation with expectation.

There are several possible reasons for the unexpected results in this series of experiments. It is possible that the various anti-H-2 sera do not have comparable capactities for staining tissue sections. An antiserum which is most effective in the cytotoxic test, the criterion by which the anti-H-2 sera were selected, may not be necessarily most effective in labeling tissue sections. Also individual anti- $\mathrm{H}-2$ sera show variation in their specific staining of different samples of the same organ and H-2 type. Nonuniform methodologies of freezing, mounting, and further processing of tissue sections may affect their antigenicity and/or their nonspecific binding of reagents. Liver tissue particularly might suffer alteration of its $\mathrm{H}-2$ antigenicity due to a factor released from lysosomes (Manson et al. 1968).

Low intrinsic antigen levels in some organs and on certain cell types within an organ may also contribute to the difficulty of $\mathrm{H}-2$ detection via immunofluorescence. Kupffer cells of liver absorb anti-H-2 sera more efficiently than do hepatocytes on a per weight basis (Basch \& Stetson 1963 , Edidin 1972). This phenomenon could explain the difficulty we have in observing stain on hepatocytes.

Different subsets of $\mathrm{H}-2$ antigens may be absent in certain tissues although they are all present in a lymphoid tissue such as spleen. Partially reacting alloantisera, in particular, might be specific only for a subgroup of $\mathrm{H}-2$ antigens not present in a particular tissue. It is possible that absorption studies do not adequately address this issue because of passenger lymphocyte contamination. In fact some blastocyst derived cell lines show a quantitative reduction or possible absence of certain $\mathrm{H}-2$ specificities present in normal adult lymphocytes of the same genotype (Ostrand-Rosenberg et al. 1977). Whether such phenomena occur differentially in adult tissues remains to be clarified.

We believe that the indirect immunofluorescent technique can demonstrate $\mathrm{H}-2$ antigens in tissue sections. For tissues, such as spleen, which have a homogenous distribution of stained cells, the staining can be quantitated by photomultiplier recordings. The indirect immunofluorescent technique is most consistent for sets of positive and control alloantisera which give minimal background stain and high levels of specific stain.

\section{Acknowledgments}

We are grateful for antiserum provided by Chella David and for Gelvatol 20-30 donated by the Monsanto Chemical Company. We acknowledge Dr. Michael Deegan's valuable suggestions for the conduct of these experiments, and Dr. Michael Edidin's advice for the preparation 
of this manuscript. We thank Cheryl Elston, Dierdre Smith, and Gay Lilly for technical assistance. We also thank Judy Schaffer for typing the manuscript.

This research was supported by NCI Grant CA18638 to Dr. Jane Schultz and the Medical Research Service of the Veterans Administration.

\section{References}

Amos, D.B. (1976) Cytotoxicity testing. NIAID Manual of Tissue Typing Techniques, eds. Ray, J.G., Ware, D.B., Pedersen. P.D. \& Mullally, D.I., pp. 25-29. Department of Health Education and Welfare, Bethesda.

Barnes, R.D., Holliday, J. \& Tuffrey, M. (1974) Immunofluorescent and elution studies in tetraparental NZB-CFW chimeras and graftversus-host diseased NZB. Immunology 26, 1195-1206.

Basch, R.S. \& Stetson, C.A. (1963) Quantitative studies on histocompatibility antigens of the mouse. Transplantation 1, 469-480.

Edidin, M. (1972) The tissue distribution and cellular location of transplantation antigens. Transplantation Antigens, eds. Kahan, B.D. \& Reisfeld, R.A., pp. 125-140. Academic Press, New York.
Gervais, A.G. (1968) Detection of mouse histocompatibility antigens by immunofluorescence. Transplantation 6, 261-276.

Gervais, A.G. (1972) Further studies on the histological distribution of $\mathrm{H}-2$ antigens. Tissue Antigens 2, 227-231.

Klein, J. (1975) Biology of the mouse bistocompatibility-2 complex, pp. 329-339. Springer-Verlag, New York.

Kwapinski, J.B.G. (1972) Methodology of immunocbemical and immunological research, pp. 606-607. Wiley-Interscience, New York.

Manson, L.A., Mickey, C.A. \& Palm, J. (1968) H-2 alloantigen content of surface membrane of mouse cells. Biological properties of the mammalian surface membrane, ed. Manson, L.A., pp. 93-112, Wistar Institute Press, Philadelphia.

Ostrand-Rosenberg, S., Hammerberg, C., Edidin, M. \& Sherman, M.I. (1977) Expression of histocompatibility-2 antigens in cultured cell lines derived from mouse blastocysts. Immunogentics 4, 127-136.

Address:

Dr. Jane S. Scbultz

Department of Human Genetics

University of Michigan School of Medicine

1137 E. Catherine Street

Ann Arbor, Michigan 48109

U.S.A. 